\title{
The role of microsilica in sustainable concrete
}

\author{
Robert Lewis* \\ Elkem Silicon Materials
}

\begin{abstract}
This paper reviews at the way we approach sustainability with concrete construction. It looks at the current thoughts on how to achieve this and asks if we are trying to be too green and actually potentially causing problems for the future. It reviews projects around the world that are using multiple cementitious blends to achieve long term durability and reduced construction costs. The point is raised that despite a drive to be green and be sustainable, the criteria for many projects is still the cost per cubic metre.
\end{abstract}

\section{Introduction}

Sustainability in construction is not just about the concrete - although concrete is the main target for criticism levelled at the building industry. It is about getting the best use of all our construction materials, with less damage to the environment as we build.

It is about building something as efficiently as possible, so that will do its job, for as long as possible, and with materials that have the least effect on our environment. It's all about doing that with cost efficiency. That does not mean as cheaply as possible, but at the price that gives the best lifetime value.

There are many people in this world who simply do not like concrete. The reasons range from the practical to the aesthetic. The major point always cited, is that concrete uses Portland Cement and production of cement is the worst source of 'manufactured' $\mathrm{CO}_{2}$ on the planet. QED all concrete is bad for the environment. Concrete uses Natural resources: Aggregates and Drinking Water: QED all concrete is bad for the environment. Concrete is grey and ugly. Yet it is the worlds most used construction material and some of the world's most magnificent buildings are constructed in concrete.

There is also an overview that all concrete is the same. It is made out of cement, stone, sand and water, it's grey and sticky and goes hard, and when it has set it has no beauty - it's just like grey boulders or building blocks. This simply adds to the thought that it is all the same product and therefore should all cost about the same

\footnotetext{
* Corresponding author: robert.lewis@elkem.no
} 
and therefore, the cheapest is probably going to do the job anyway, so why pay more? Sadly, that has often been reflected in the collapse of buildings and other constructions that should have had more resilience. A number of times, the author has worked on specifications for high durability and long lifetime concretes, only to have the designs turned around by the time construction starts, because: "Well, we decided we don't really need that performance" and "We can get almost the same from this mix, and it saves $\$ 5$ a cubic metre". If that performance was needed in the first place, then it probably still is needed - and it is not price per cubic metre you need to consider - it is total construction and lifetime costs.

\section{Concrete needs to be 'Engineered'}

The concrete we use has to be designed to give the right performance, not just when it has set and is 'in the building'. It needs to be thought of from the very point of when it arrives on site:

In the plastic state: how long will it last at a certain workability; how is it going to be conveyed / placed / finished / cured? These are all criteria for the rheology of the mix.

As it sets: how fast / slow does the setting need to be; how much temperature rise can be tolerated?

When it has set - how soon does it need to reach a critical strength; what ultimate strength is required; flexural, tensile, creep values?

For the conditions it is placed in: what resistance to the ingress of chlorides, sulfates, water, other chemicals; abrasion or water erosion, physical impact, temperature changes?

How long is it expected to last before repair or replacement: 50 years, 100, 200, 800 ?

All of these factors need to be taken into consideration to design the concrete mix. It is no good designing something in the laboratory that is either impractical to produce or impractical to handle. The last line on any concrete site is the person who works to place, compact, finish and cure it. If that person is not able to do any of those things easily, then chances are they won't get done properly - and a 'perfect' concrete is destroyed. The better the design, the easier the concrete is to use, the less concrete consumed and the longer it lasts. The longer it lasts, the less resources we use because we don't have to re-build it in 10 or 20 years' time. This is where the engineering - to design for purpose - comes in, to enable us to get the optimum for what we want to do. All these things add up - to give less cost - while achieving the best performance:

Improved Plastic Properties: ease of placing, faster construction, less machinery

$=$ Better Economics.

Increased Strength: faster construction, less volume

$=\underline{\text { Better Economics. }}$

Increased Durability: increased lifetime, fewer repairs

$=\underline{\text { Better Economics. }}$

Combining the key points: less machinery, less volume, fewer repairs $=$ less impact on the environment

$=\underline{\text { Sustainability. }}$ 


\section{Sustainable resources for concrete}

Cement: Improvements to production processes have reduced the carbon footprint of Portland cement. Higher qualities are now being designed and blended to give different qualities for varying applications. However, pure Portland cement, no matter the current process, will still yield around 800 to $900 \mathrm{~kg}$ of $\mathrm{CO} 2$ for every tonne of cement produced. Therefore, if we can use less pure Portland we will reduce the impact of the environment.

Supplementary Cementitious Materials (SCMs): These are by products from other industrial processes, such as fly ash from coal fired power stations; ground granulated blastfurnace slag (GGBS) from steel making; microsilica from ferrosilicon production and metakaolin from clay refining. These are the major Type II additions - latent hydraulic and pozzolanic binders. The use of these materials can replace large volumes of Portland cement and contribute differing levels of effect on rheology, and long term properties. Designed use can significantly improve such characteristics as strength and impermeability leading to much higher performance concrete. By needing less Portland cement to achieve the requirements of the concrete, the carbon footprint can be greatly reduced.

Use of Aggregates: These are an obvious natural resource and we need to slow down the rate of quarrying, bringing down mountains and dredging the sea, to get fresh new aggregates each time we need to make some concrete. The use of recycled aggregates (RCA) has been shown to be perfectly effective in new concrete. So much so that trials with 50\% RCA have given equal performance to concretes with $100 \%$ new aggregates. As buildings and such have to come down to allow new ones to go up, we should be improving the processing and use of recycled aggregates to reduce our consumption of new material. Lightweight aggregates are often made from waste material and can be used very effectively in concrete. Improved designs mean that structural strength lightweight concretes - circa $60 \mathrm{MPa}+$ at around $1900 \mathrm{~kg} / \mathrm{m} 3$ can be produced. This means bridges and larger projects can use less normal weight concrete - giving less dead weight to the structure and enhancing insulation in buildings. This latter point can have a further impact by reducing the need for heating and cooling.

Water: Is precious, especially drinking water, and that is what we use for making concrete. Admixtures are now made that can drastically reduce the amount of water needed per cubic metre. Better design of the concrete, using particle packing can also mean less water. Greater use of recycling units on plants and major projects means that a lot of water can be recovered and re-used, saving more fresh water.

Optimising the design: Engineering the concrete for the particular qualities needed can mean reductions in volumes produced: Using higher strength to reduce the column and slab sizes; better rheology to enable less machinery; durability for the lifetime expected, meaning less repairs and no rebuilds, means less volume of concrete overall, which impacts on all the above points. 


\section{Cementitious steps towards sustainability}

To reduce our carbon footprint, the first and easiest way is to remove cement, but this can only be taken so far. To make concrete we still need cement, or more correctly, the free lime from the cement hydration, to activate the SCMs that we are putting in to replace the cement taken out. We then have the decision of how much we replace. The more we replace with fly ash and ggbs, the slower the concrete gets, in terms of setting and strength gain - and durability performance. If we want high performance, or high level properties at an early age, we need a good balance of cement and SCM's.

It is nice to think of cement free materials - geopolymers and such - but these materials are not in mass production and, just because they don't have portland cement in them, does not mean they are 'greener':

(When all things are taken into consideration) “....it appears that geopolymer concrete has a similar impact on global warming to standard concrete." 1

As such, we need to consider the designs of our concrete mixes, and engineer them to achieve ALL the characteristics we want - and we need to do this while also considering the total life costing of the project. Use of software programs such as Life365 has increased rapidly over the last few years - and the data produced has shown that most projects may seem to cost more to start with, but cost less in terms of total value. Some projects, though using more expensive concrete, have shown that even the initial construction cost is reduced, let alone the long term costs.

\section{Supplementary cementitious materials}

Most people are aware of the three major materials here. Metakaolin and Limestone Fines are sometimes included in this list. However, metakaolin does have a processing energy cost and limestone fines are only marginally pozzolanic, so the concentration here is on low environmental impact and normal to high pozzolanic reactivity. To run a basic recap:

Fly Ash is collected from coal-fired power stations. It has a silicon dioxide $\left(\mathrm{SiO}_{2}\right)$ content of around $40 \% \sim 50 \%$ and is a similar particle size to cement. The replacement rate is normally from $15 \%-50 \%$, to achieve improvements in rheology, heat reduction, and give long-term durability benefits.

GGBS is a by-product from the steel industry and is normally ground to a particle size roughly the same as cement. For some applications it can be ground finer than cement and this will increase the reactivity. The $\mathrm{SiO}_{2}$ content is usually $35 \% \sim 40 \%$.

As ggbs is weakly hydraulic as well as pozzolanic, the replacement rate can be from $25 \%-90 \%$. It is used for major heat reduction in large elements, improved longterm durability benefits.

Microsilica (also known as silica fume) is collected from the ferrosilicon industry. It has a high $\mathrm{SiO}_{2}$ content, normally between $90 \sim 95 \%$. Due to the nature of the production process for the initial product the particle size for microsilica is approximately 100 times finer than Portland cement. This gives a much higher reactivity than fly ash or ggbs and it is usually added to an original or recalculated cementitious content at between $5 \%-15 \%(\max 25 \%)$. The size, spherical shape 
and reactivity can have a range of influence on the concrete mix, improving the rheology, reducing permeability, improving strength and durability characteristics. It is often used in the cementitious blends for creating Ultra High Performance Concrete (UHPC).

Metakaolin is a similar product to microsilica. It is a fine, highly pozzolanic material produced from calcined waste clays. As such, it has an energy footprint and care should be taken in considering its sustainable aspects when used in a concrete mix.

\subsection{Use of fly ash and GGBS in high volumes}

The first thought then, if we want to reduce the $\mathrm{CO}_{2}$ our concrete causes, is to replace as much of the cement as we can with either fly ash or ggbs. Well, that is a 'yes and no'. You can't just throw them in 'blanket fashion'; the performance of the concrete, plastic, setting and final characteristics have to be taken into the design process.

It is no good designing a 'perfect' green concrete in the laboratory, if it will not work in practical terms in the real world. The design of the concrete for the towers on the Tsing Ma bridge in Hong Kong, was originally for $30 \%$ opc and $70 \%$ ggbs. This was to give low heat and high chloride resistance. As a design, on paper, technically this was good - the concrete would have low heat when produced and would, in the long term, develop high chloride resistance. The drawback was the practicality of construction, as the mix was to be slipformed to create the towers. Due to the slow rate of setting, hardening and strength development of the mix with $70 \%$ ggbs, slipforming was found to be impossible. Replacing $5 \%$ of the ggbs with microsilica improved the hardening rate and the slipforming was able to run.

A number of places, including Hong Kong and Dubai, have stipulated that concrete shall contain ggbs, to reduce the carbon footprint. The additional point to that statement is that 'equivalence' [to a Portland mix] can be achieved at 56 to 90 days. This is a point of great concern with regards to the early age and ultimate performance of the concrete. The key point here is time. Larger quantities of FA or GGBS can have great effects on setting time, hardening rate, strength gain and real time durability. While in some cases, waiting - and curing the concrete - for another two to three months - could be feasible, it is not on most projects.

\section{Real time durability}

Projects want to move forward, usually as fast as possible, but at least within reason. Waiting 56 or 90 days to see if a concrete has achieved the required strength would not be sensible on most projects - and what do you do if you've progressed 6 or 7 floors upwards and the concrete in the columns of floor one has not achieved the required strength?

It is not only strength, but it is also the durability characteristics. The 'equivalence' at 56 or 90 days is tested on lab samples. These are concretes that have been carefully cured for that length of time. These are the best results you can get for that concrete, kept under the best conditions. What is the actual, in-situ, concrete achieving? Has it been cured for the same length of time? Has it developed the impermeability you require? If it is facing the ground conditions where it needs a 
water resistance of less than $5 \mathrm{~mm}$, but is known only to reach that level of resistance at 56 days, how much has it been affected in the 56 days it has already been exposed? If you add chlorides and sulfates in to that equation as well, and the potential of 90-day equivalence, the possible failure of the concrete becomes very likely. A concrete in situ, once 'attacked' by the environment in the early ages, will never achieve the same results as that 'perfectly cured' concrete in the lab.

In some case, yes, there may be a time window where concrete can be stored and cured, or cured in-situ for a length of time, but the likelihood of that being 56 to 90 days is very small.

So, yes, while we can use good quantities of these products - but the mixes have to be engineered to give the required performance, from the start. This is where the addition of microsilica to such mixes can result in major improvements.

\subsection{Being green for green's sake}

While it is nice to think about how we can use 'green' environmentally friendly products, there is no point in going for such materials if they aren't sustainable! It defeats the object:

The First Platinum LEED project on the East Coast of the USA, had to replace the cladding on the building in less than 5 years, because it wasn't durable enough. It was replaced with concrete...

At a previous conference, a speaker from China said they wanted construction to use more bamboo cladding, because it grows faster than current use. When asked "Have you calculated the balance point - when accelerated new use, and subsequent repair, exceeds the regrowth rate?" the answer was "I don't know - I don't believe we've thought about that"...

Unless we use these products wisely, we actually stand more chance of doing harm rather than good. The same goes for our concrete. We want it to have higher performance, but we also want it to be a sustainable as possible. We have to find the balance.

\subsection{Balance in the design}

If we want to achieve practical results and keep our $\mathrm{CO}_{2}$ and environmental impact low, then we need to achieve the balance between levels of additions that will give us these factors. That is, without compromising the setting, hardening and 'real time' early age durability we can use the following levels of replacement and addition:

Between $20 \%$ and $30 \% \mathrm{FA}$ - in combination with 8 to $10 \% \mathrm{MS}^{2}$

Or $40 \%$ to $60 \%$ GGBS - in combination with 6 to $10 \% \mathrm{MS}^{3}$

We can also use $20 \%$ to $50 \%$ percentage of recycled aggregates and the recycled wash down water. The use of particle packing software to blend the aggregates and cementitious materials will give us the best rheology - and can often achieve a reduction in the total cementitious content.

There is nothing new to Pozzolanic Concrete - the Romans used volcanic ash and aggregates, mixed with lime over 2,000 years ago, and the Pantheon and similar buildings still stand today, so we know how to do this. We have been using binary blends - opc/fa and opc/ggbs - for almost a century. In the last 50 years that has expanded to opc/ms binaries and then to ternary and quaternary blends, using all the 
SCM's. We are using the synergistic effects of these materials to engineer even better concretes. It is no longer the case of asking "Should I use FA, or GGBS, or MS?" It is "What's the best combination to give me the performance I need?"

\section{Research and real life}

In 1991, Elkem undertook a study of comparative concretes in the UK - with and without the addition of microsilica. The trials were overseen and testing conducted by Messrs Sandberg.

Based on a $400 \mathrm{~kg} / \mathrm{m}^{3}$ cement content at around $0.42 \mathrm{w} / \mathrm{c}$ ratio the mixes were opc; opc + ms (40kg addition); opc/ggbs at 50:50; opc/ggbs + ms; and an src mix to show comparative sulfate resistance. Two sets of variation on the opc mixes were done, one with a change of aggregate and one with steel fibres. The full results are compiled in the Sandberg Report, which was presented as a paper in $1993^{4}$. The basic strength and durability results are shown in the graphs, listed 1 to 5 . The results showed that even when using a 50:50 blend of ggbs - which achieved good results - the performance could be significantly improved by the addition of the microsilica especially at early ages as shown by the graph on compressive strength. While only performed in this run with ggbs, subsequent 'real-life' projects have shown that the triple combination with fly ash is equally effective. Following on from the research, based on its findings, a number of projects were guided to use triple blend cementitious materials and have achieved very high levels of durability performance.

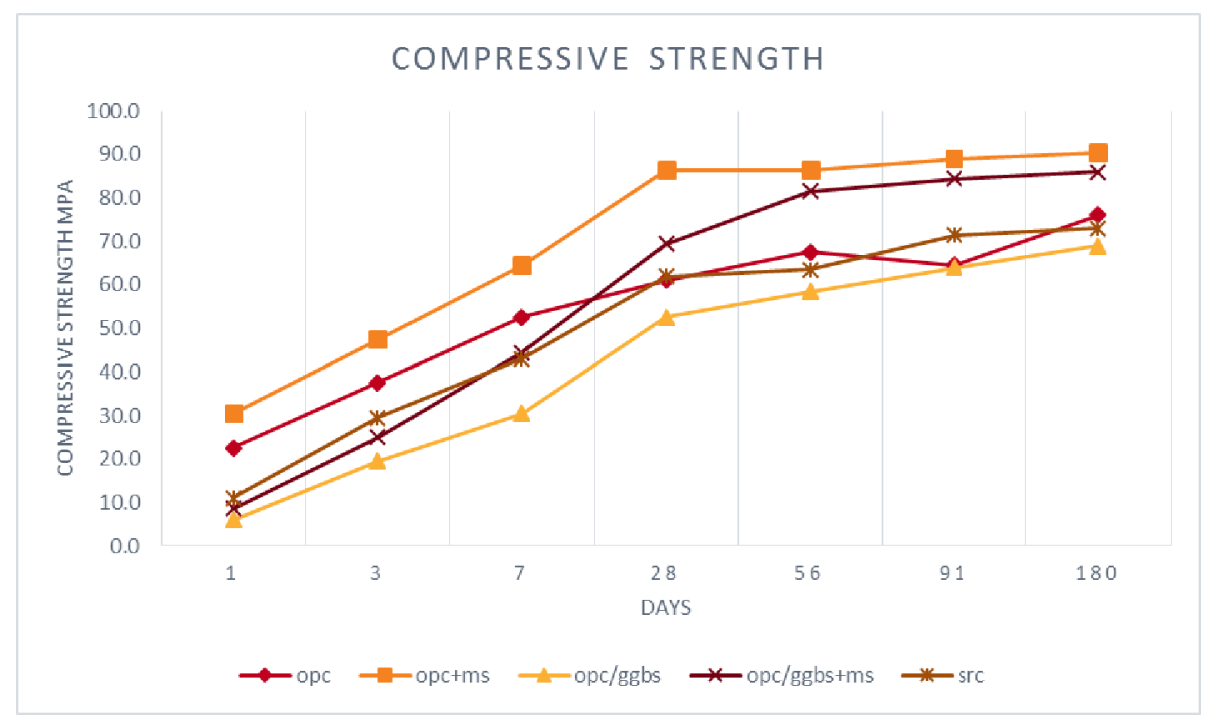

Fig. 1. Compressive strengths of test cubes from Sandberg; ref 4. 


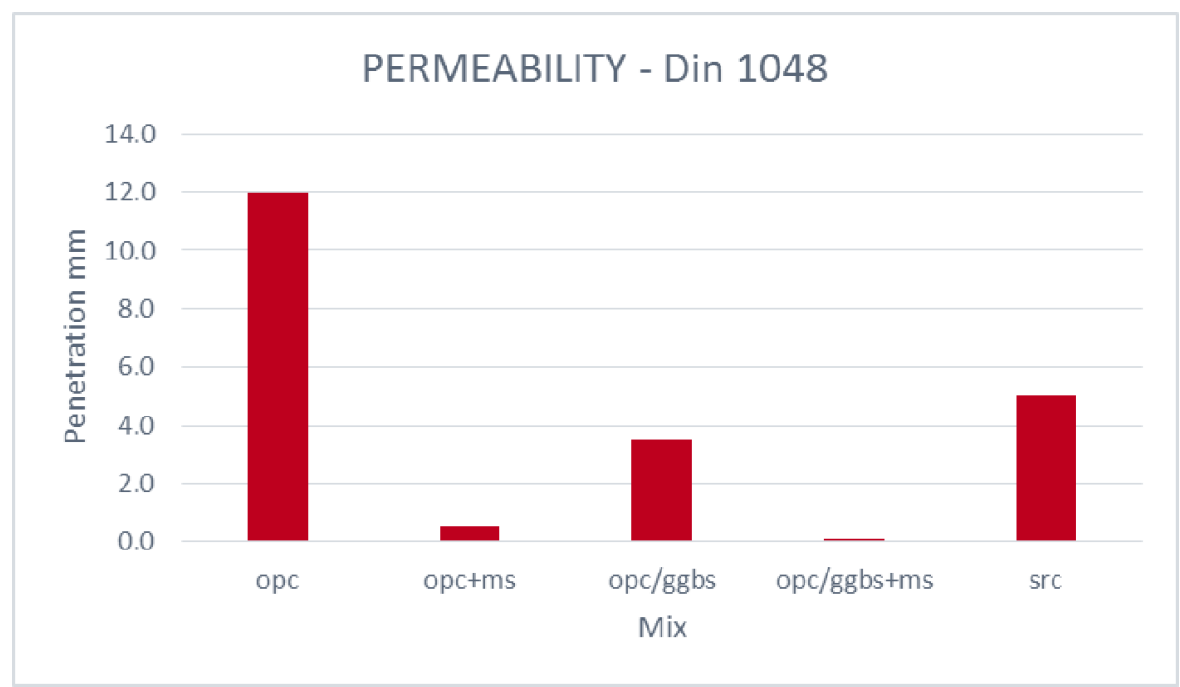

Fig. 2. Water permeability at 28 days, to DIN 1048, from Sandberg, ref 4.

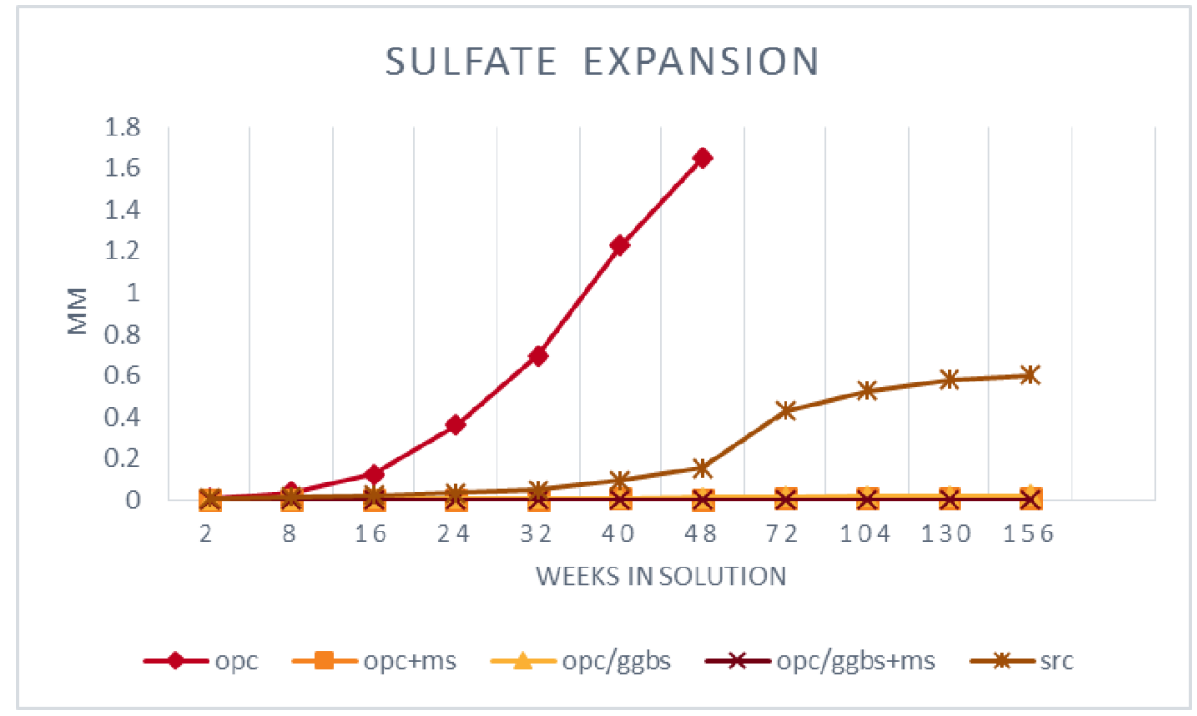

Fig. 3. Expansion of mortar prisms, from Sandberg, ref 4. 


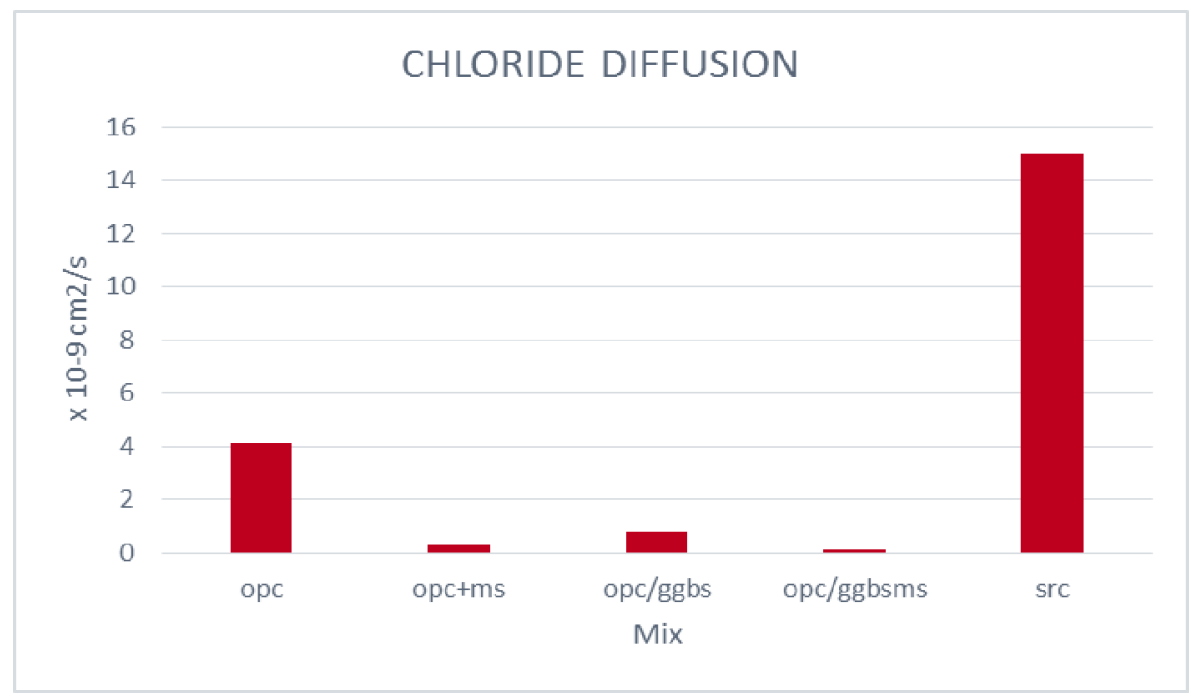

Fig. 4. Chloride Diffusion, 90 day ponding test, from Sandberg, ref 4.

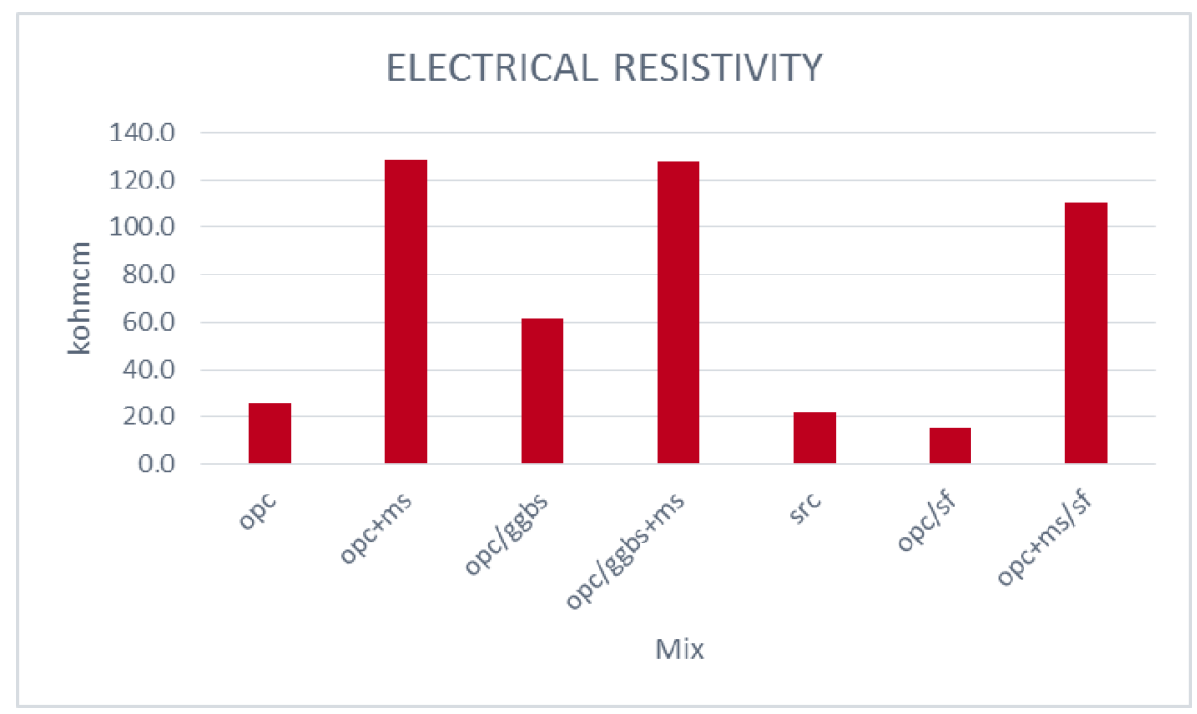

Fig. 5. Electrical Resistivity, kohm/cm, from Sandberg, ref 4. (it should be noted here that this test meter only read up to 128 . Real life testing has shown values over 500 ).

\section{Project references}

\subsection{Singapore metro and DTSS}

The twin tunnels between Somerset and Newton Circus Stations on the MTR were cast in 1986. One tunnel was cast using a Sulfate Resistant Cement concrete with $400 \mathrm{~kg} / \mathrm{m} 3$. To protect this concrete from being attacked by the sulfate rich acidic groundwater, it was covered with a membrane. The other tunnel was cast with an 
opc mix using $10 \%$ microsilica at the same cementitious content. This tunnel was cast without a membrane. After 15 years it was clear that the sulfate resistant concrete was failing, while the microsilica concrete was showing no signs of attack. The success of this 'in-situ' trial lead to the use of microsilica concrete for the Deep Tunnel Sewage System that would cover the whole island.

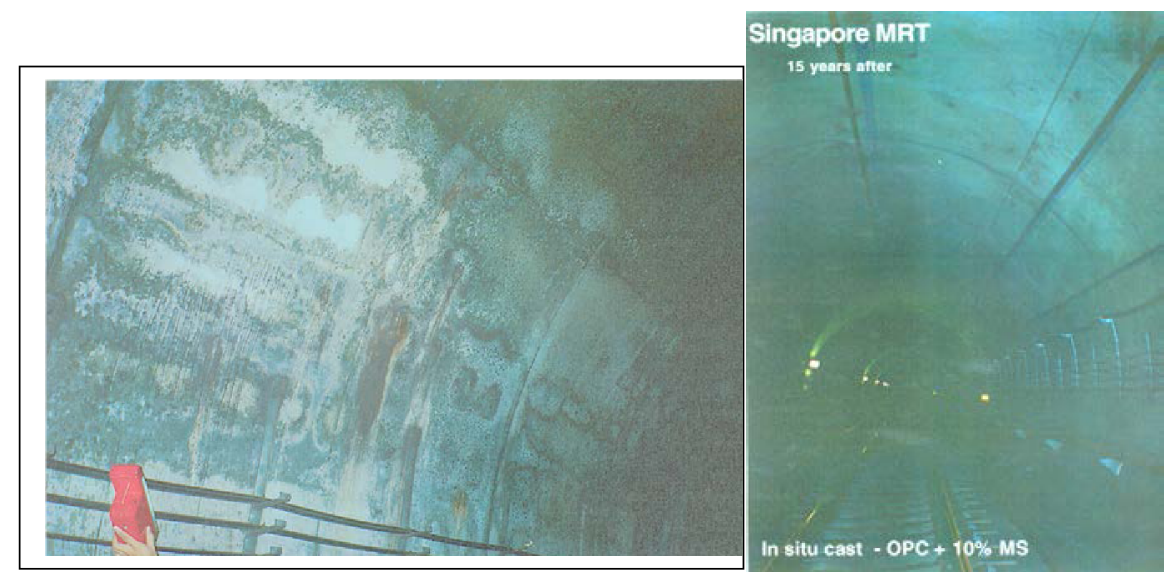

Fig. 6. Pictures of the two tunnels after 15 years in use.

\subsection{Offshore and bridges}

Marine environments were an early target for the use of microsilica concrete. A small addition, up to $3 \%$, would improve the rheology of pumped concretes so that great distances - often vertically in the case of slipforming oilrigs - could be achieved. The high chloride resistance and synergy with fly ash and ggbs meant that mass pours could be done with low heat evolution and the high strength capabilities meant that even lightweight concrete could be produced with structural strengths.

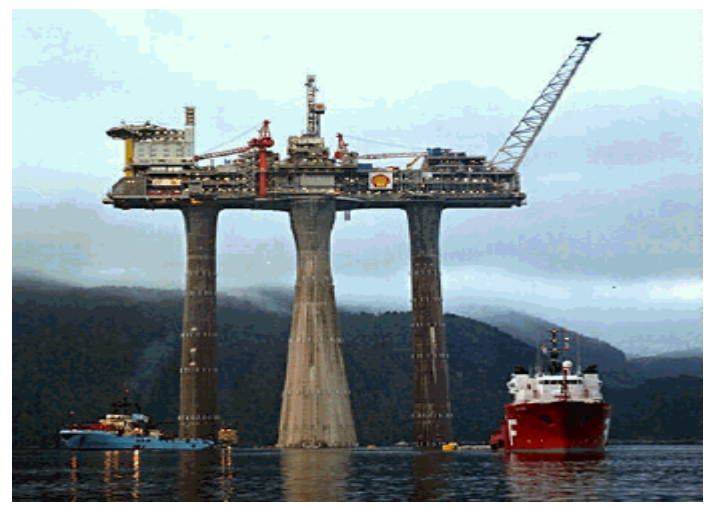

Fig. 7. The Troll Platform being towed out into the North Sea 

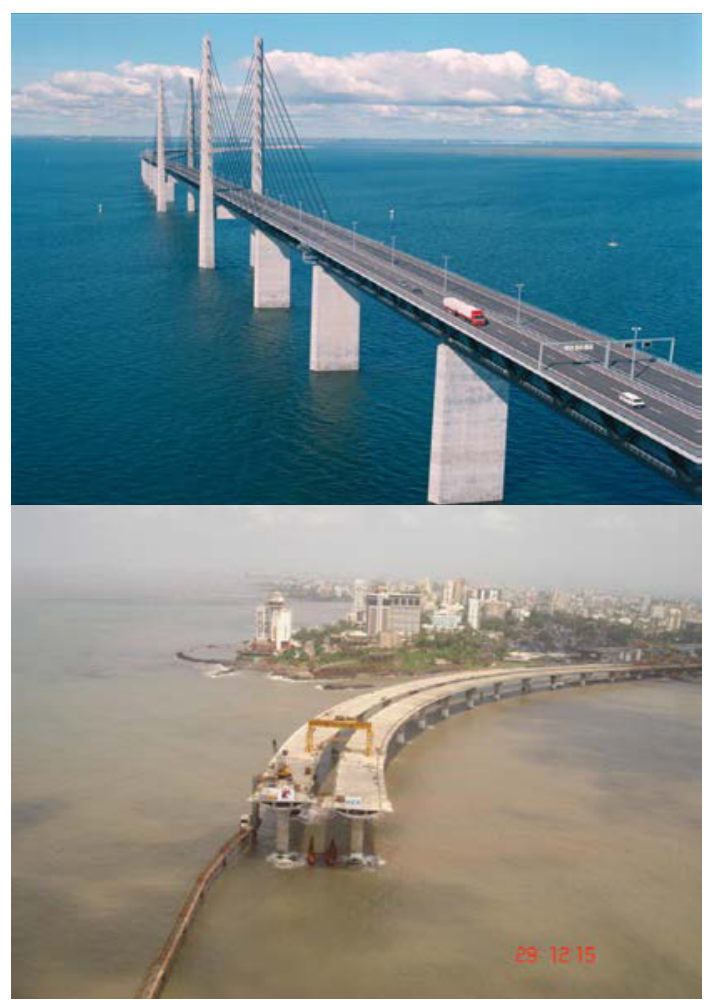

Fig. 8. The Oresund Bridge, between Denmark and Sweden and Bandra-Worli Sea Link in India. Both these projects used binary blends of opc $+\mathrm{ms}$ and triple blends of opc $+\mathrm{fa}+\mathrm{ms}$. 


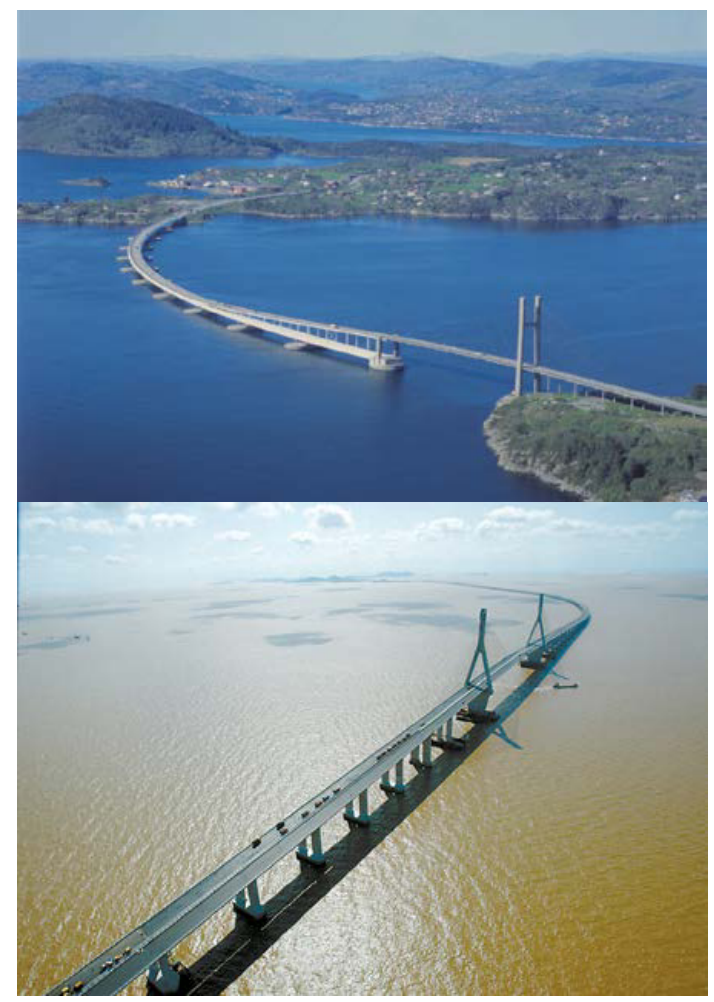

Fig. 9. Nordhordland Bridge - lightweight concrete: $55 \mathrm{MPa}$ at $1900 \mathrm{~kg} / \mathrm{m} 3$ was used to construct this floating bridge. The East Sea Bridge in Shanghai (right) is $32 \mathrm{~km}$ long and used triple and quad cementitious blends in the two Marine Concretes used for the construction.

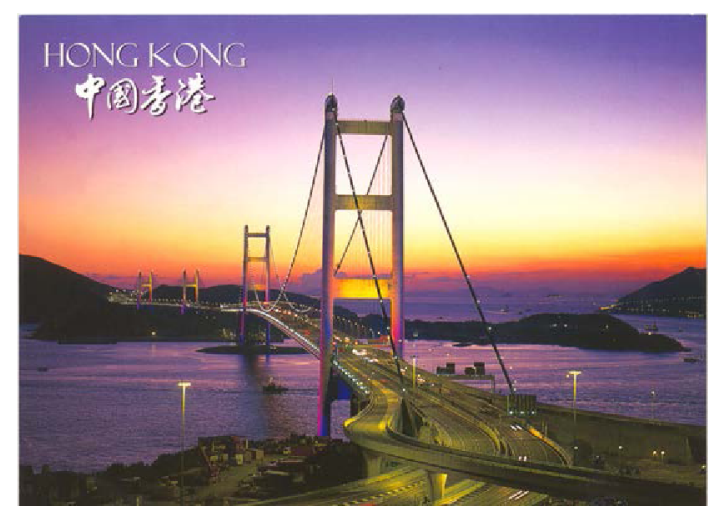

Fig. 10. Tsing Ma bridge, Hong Kong, 1997.

\subsection{Tsing Ma bridge.}

This suspension bridge was one of the first to use a low heat ggbs mix, while slipforming the two $206 \mathrm{~m}$ tall suspension towers. The original design was for $70 \%$ ggbs as a binary mix with opc, but when it was found that this did not set and harden 
fast enough, 5\% ms was added to give the concrete a 'kick' and allowed slipforming to proceed. Other concretes on this project also included fly ash at $25 \%$ with ms at 5\%. The success of the concrete used for Tsing Ma lead the Civil Engineering Department of the Government to create a focussed Marine Concrete Specification, that included microsilica as a specified component, in 2002. In 2013, this specification was upgraded to stipulate triple blends, with a compulsory addition of microsilica:

\subsection{Recommended specification for reinforced concrete in marine environment}

The main features of the specification are summarised as follows:

The minimum characteristic strength of the concrete mix shall be $45 \mathrm{MPa}$.

The maximum water/cementitious ratio shall not exceed 0.38 .

Condensed silica fume is to be added to reduce the permeability of the concrete.

The cementitious content shall be $380-450 \mathrm{~kg} / \mathrm{m}^{3}$, including $5-10 \% \mathrm{CSF}$, with either: FA at $25-40 \%$, or GGBS at $60-75 \%$.

The cover to all reinforcement in all exposure zones shall be $75 \mathrm{~mm}$.

\section{Sustainability and the role of microsilica}

There are a number of things we can do to our concrete to make it sustainable. Utilising the SCMs and in particular designing triple bends gives us unique ways to tailor concrete to the best plastic and hardened properties for the work we need it to do. We can optimise the mix for:

Rheology - make it as easy as possible to handle, place and finish;

Strength - use higher strengths to allow wider spans, thinner columns, use of lightweight aggregates;

Physical Durability - improved wear and tear resistance means it will last longer, needing less repairs or rebuilds;

Chemical Durability - the better the resistance the longer lifetime, particularly in areas where repairs or rebuilds might be hazardous.

But in all these instances it is a matter of collaboration between all parties to understand what needs an has to be done to complete the project. If that happens, the results can be surprising.

\subsection{South Wacker drive, Chicago}

In this project the client wanted to have an innovative building, making the best use of the space and getting good value for money. The architect and the consultant worked with the ready-mix producer to ensure that if they could get a very high strength concrete, they could make design changes. The ready-mix supplier did trials, involving both the additions (microsilica) and the admixtures (superplasticisers) suppliers and said yes, this was feasible. The columns were reduced in size - so that the same dimensions were used for the whole building. High strength concrete was used for the first fourteen floors and then even with reducing strength design, the microsilica was kept in the mix to allow pumping to the top of the building $-273 \mathrm{~m}$. These actions saved formwork, setting up time, 
pumps (only one was used) and 7,650m 3 of concrete and 3,000 tonnes of rebar. The environmental value of the concrete saved alone was:

\begin{tabular}{ll} 
Cement & 3,000 tonnes \\
Coarse Aggregate & 7,650 tonnes \\
Fine Aggregate & 5,250 tonnes \\
Water & $1,071,000$ litres \\
\hline
\end{tabular}

About 1,000 truck movements / wash-downs...

However, the high performance concrete was $50 \%$ extra per $\mathrm{m}^{3}$. This was not a problem, because the building was finished ahead of time, for less cost than the original design, and the owner got more rentable space. The cost per cubic metre for the concrete did not enter into the equation, as it was irrelevant to the final cost.

\subsection{The Burj Khalifa}

Currently the world's tallest building, this amazing statement of design and accomplishment has concrete at its feet and in its heart. A triple cementitious blend is the starting point - moderate sulfate resisting portland cement, fly ash and microsilica.

Despite needing high strength and pumpability, as well as high durability for the desert ground the foundations will sit in, the total cementitious content was only $450 \mathrm{~kg} / \mathrm{m}^{3}$. Stringent durability requirements were laid down including three variations of test for water ingress. A major part of the trials was to test the pumpability of the mix - which proved successful as the concrete was transported over $600 \mathrm{~m}$ vertically through one pump. Strength results were as expected as were the durability numbers. Consideration here was given to the fact that this first World's Tallest Building to cross the $800 \mathrm{~m}$ mark was durable enough to last at least 100 years. The next World's Tallest Building will be the Jeddah Tower, in Saudi Arabia - which is using the same design of concrete.

Specification for the 60MPa piling (Baseline specification for all concrete).

Compressive Strengths:

45 to $80 \mathrm{MPa}$

Minimum Cement:

$252+168+30 \mathrm{~kg} / \mathrm{m}^{3}(56: 37: 7)$

$\mathrm{W} / \mathrm{C}$ ratio:

0.34

Flow (at site):

$>600 \mathrm{~mm}$

Water Penetration

$<10 \mathrm{~mm}(\mathrm{BS}$ EN $12390-8)$

Water Absorption

$<1.5 \%$

RCPT

$<1200$

(BS 1881:122)

Water Permeability

$<5 \mathrm{~mm}$

(AASHTO T-277)

Results.

(Din 1048)

$(\mathrm{MSRPC}+\mathrm{FA}+\mathrm{MS})$

Compressive Strengths (150mm cubes - averages)

$\begin{array}{ll}7 \text { days } & 40.5 \mathrm{MPa} \\ 14 \text { days } & 51.5 \mathrm{MPa} \\ 21 \text { days } & 60.5 \mathrm{MPa} \\ 28 \text { days } & 64.5 \mathrm{MPa} \\ 56 \text { days } & 75.5 \mathrm{MPa} \\ \text { Water Penetration } & \text { Zero } \\ \text { Water Absorption } & 0.7 \% \\ \text { RCP Test } & 590 \\ \text { Water Permeability } & \text { Zero }\end{array}$




\subsection{Roadway pavement}

With the enthusiastic use of de-icing salts and chemical to remove the ice and snow from our roads, it is not surprising that we get chloride attack on bridge decks and easily rutted roadways. In the United States alone there are rumoured to be a few Trillion Dollars' worth of road repairs to bring the infrastructure up to date. Hence they use cementitious blends with microsilica and microsilica with fly ash to get the durability they need.

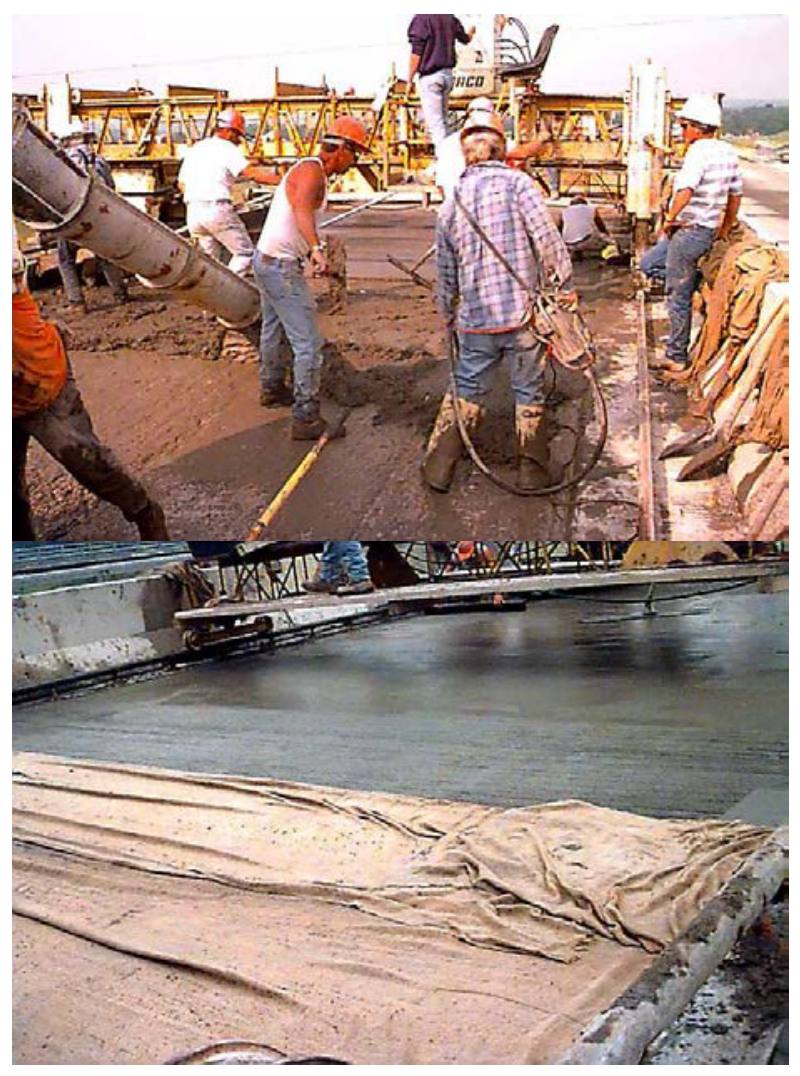

\subsection{Bridge deck - New York state DOT}

The concrete used here has been designed to resist chloride ion penetration \& minimize cracking - hence the triple blend: fly ash to reduce the temperature and microsilica to seal against chlorides. The basic mix design and curing requirement were:

OPC

Fly Ash

MS

W/B

Slump

Air

Wet Cured for 7 days.
$300 \mathrm{~kg} / \mathrm{m} 3$

$80 \mathrm{~kg} / \mathrm{m} 3$

$25 \mathrm{~kg} / \mathrm{m} 3$

0.40

$75-100 \mathrm{~mm}$

$6.5 \%$ 
In the UK, a major trial of high strength triple blend concrete was conducted in the early 1990 s to show that a continuous concrete road was viable - with the potential for low wear and high lifetime. The trial was for Ecopave and worked well. It is interesting to note that the USA has taken on high strength pavement, with skid resistant tines 'ground' in while the UK has not. The Ecopave mix was: $\left(\mathrm{kg} / \mathrm{m}^{3}\right)$

Low Alkali Cement 260

Fly Ash $\quad 55 \quad(16 \%)$

Microsilica $\quad 20 \quad(6 \%)$ (335 total binder)

Sand 0-2 673

Stone 4-8 $\quad 388$

Stone 8-11 1055

Super (Conplast 212) $\quad 4.2$

Water 87

$\mathrm{W} / \mathrm{C} \quad 0.26$

Comprssive strengths:

$\begin{array}{ll}3 \text { days } & 60 \mathrm{MPa} \\ 7 \text { days } & 70 \mathrm{MPa} \\ 28 \text { days } & 95 \mathrm{MPa}\end{array}$

\subsection{Indianapolis international airport parking garage}

A simple 5 floor open plan structure, and the easiest way to show that durable environmentally friendly concretes can be done without compromising the 'buildability'. The garage has 7,100 spaces. To be built in the standard fashion this would have cost $\$ 15,000$ per space. By redesigning to use a concrete with opc, fly ash and microsilica, recycled aggregates and with optimised particle packing, they achieved a LEED rating and saved concrete volume and time. At the end of construction, the actual cost was only $\$ 12,000$ per space.

That amounts to a saving of $\$ 21.3$ million. That is the saving on construction. The long term durability could save up to $\$ 40,000$ a year in maintenance costs as well. 


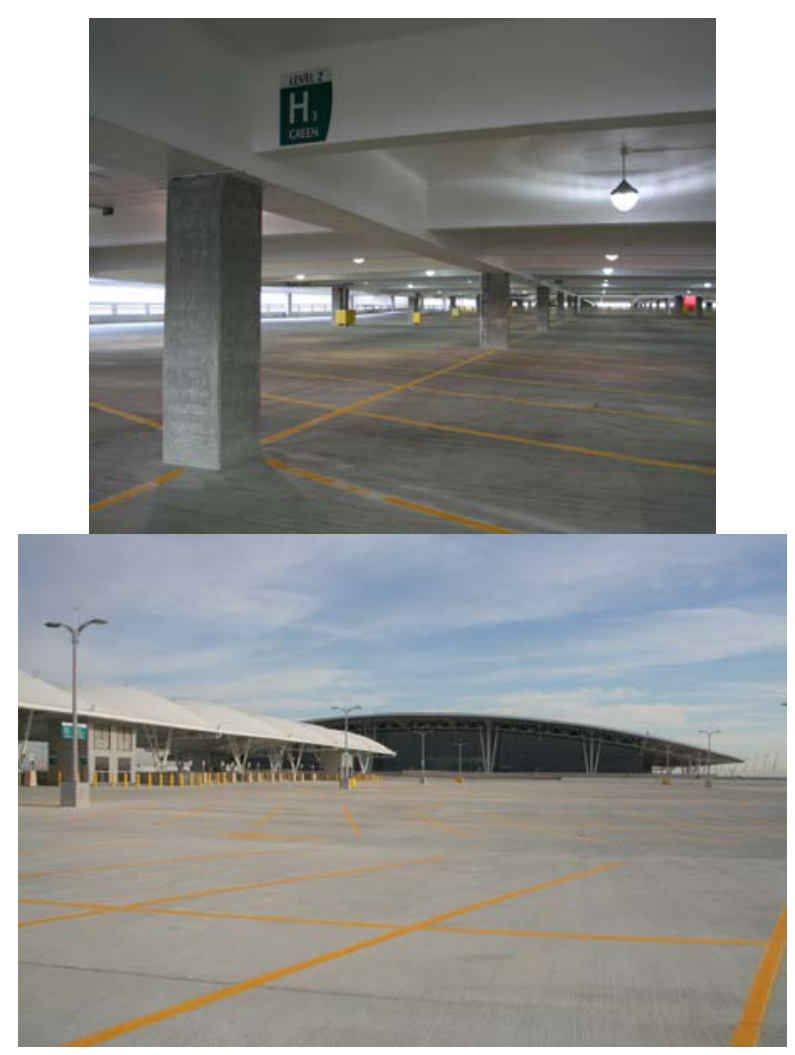

Fig. 11. The interior and top level of Indianapolis Airport Car Parking. Note the space for vehicles and the visual light. No painting on the surface, even on the top level, just the parking bay lines.

\section{An essential role}

While we can use products like flay ash and ggbs to give us 'green' concrete, if we need the high performance and qualities that modern construction demands, then the addition of microsilica becomes an essential part in our concrete design.

This is because we cannot wait for 56 days or 90 days or longer for the concrete to achieve strength and resistance values needed in-situ.

Microsilica concretes have been used for more than 30 years to improve performance and sustainability in major projects across the globe. The research and the reality are there to be seen. It is our job to get things right, because we should remember that sustainability is not for us, it is for our children and grandchildren and their grandchildren.

\section{References.}

1. Habert et al; An Environmental Evaluation of Geopolymer Based Concrete Production: Reviewing Current Research Trends - Journal of Cleaner Production · July 2011. 
2. Unpublished Thesis dissertation, Loughborough University, 2016.

3. John P.H.Frearson: Microsilica Concretes-Trial Mix and Test Data -Final Three Year Report. Sandberg report number X/602/45; 